\title{
Three approaches to optimize optical properties and size of a South- facing window for spatial Daylight Autonomy
}

\author{
Tuğçe Kazanasmaz ${ }^{\text {a, * }}$, Lars Oliver Grobe ${ }^{\text {b }}$, Carsten Bauer ${ }^{b}$, Marek Krehel ${ }^{\text {b }}$, \\ Stephen Wittkopf ${ }^{\mathrm{b}}$ \\ a Department of Architecture, Izmir Institute of Technology, Urla, 35430 Izmir, Turkey \\ ${ }^{\mathrm{b}}$ Competence Center Envelopes and Solar Energy, Lucerne University of Applied Sciences and Arts, 6048 Horw, Switzerland
}

\section{A R T I C L E I N F O}

\section{Article history:}

Received 5 February 2016

Received in revised form

11 March 2016

Accepted 15 March 2016

Available online 17 March 2016

\section{Keywords:}

Daylight

Redirection

sDA

Window design

BSDF

Radiance

\begin{abstract}
A B S T R A C T
This study presents optimization approaches by a recent Climate-Based-Daylight-Modeling tool, EvalDRC, to figure out the necessary area for a daylight redirecting micro-prism film (MPF) while minimizing the glazing area. The performance of a window in terms of spatial Daylight Autonomy (sDA) is optimized by its geometry and optical properties. Data implemented in simulation model are gathered through on-site measurements and Bidirectional-Scattering Distribution Function (BSDF) goniomeasurements. EvalDRC based on Radiance with a data driven model of the films' BSDF evaluates the window configurations in the whole year. The case to achieve an sDA of at least 75\% is a South-facing window of a classroom in Switzerland. A window zone from $0.90 \mathrm{~m}$ to $1.80 \mathrm{~m}$ height provides view to the outside. The upper zone from $1.80 \mathrm{~m}$ to $3.60 \mathrm{~m}$ is divided into six areas of $0.30 \mathrm{~m}$ height in three optimization approaches including the operation of sunshades as well. First, the size of the clear glazing is incrementally reduced to find the smallest acceptable window-to-wall ratio (WWR). Second, microprism films are applied to an incrementally varying fraction the initial glazed area to determine the minimum film-to-window ratio (FWR). Finally, both approaches are combined for a minimum FWR and WWR. With clear glazing and WWR of 75\%, the sDA of $70.2 \%$ fails to meet the requirements. An sDA of $86.4 \%$ and $80.8 \%$ can be achieved with WWR 75\%, FWR $1 / 9$ and WWR 50\%, FWR $1 / 2$ respectively. The results demonstrate the films' potential to improve the performance of windows with reduced WWR.
\end{abstract}

(c) 2016 Elsevier Ltd. All rights reserved.

\section{Introduction}

The utilization of daylight in buildings has been a significant concern to reduce the electrical energy demand for lighting and cooling of buildings [1]. Such widely known benefits of daylight's presence are better work/or learning performance, motivation and health. However, to achieve these goals, it is necessary to control its negative impacts such as visual discomfort and glare [2,3]. The recognized importance of daylight in buildings is contrasted by the inconsistent use of terminology and planning tools by practitioners, mostly based on rules of thumbs especially in the early design stage [4]. Climate-Based Daylight Modeling (CBDM) allows quantitative performance predictions based on local weather data. The resulting

\footnotetext{
* Corresponding author.

E-mail addresses: tugcekazanasmaz@iyte.edu.tr (T. Kazanasmaz), larsoliver grobe@hslu.ch (L.O. Grobe), carsten.bauer@hslu.ch (C. Bauer), marek.krehel@hslu. ch (M. Krehel), stephen.wittkopf@hslu.ch (S. Wittkopf).
}

annual records of illuminance are reduced to comprehensive annual metrics such as Useful Daylight Illuminance (UDI) and Daylight Autonomy (DA) [5,6]. UDI defines both lower (100 lux) and upper (2000 lux) boundaries for horizontal illuminance to be counted as useful, while DA considers only the lower boundary. DA, is an annual, task-illuminance based metric of daylight performance [5-7]. It is recently named as spatial Daylight Autonomy (sDA) by IES; and is defined as "the percent of an analysis area that meets a minimum daylight illuminance level for a specified fraction of the operating hours per year" [8]. In other words, it reveals the adequate daylight on workplane area throughout the year. sDA considers not only the temporal but also the spatial dynamics of daylight in buildings. It has been recommended for the evaluation of entire occupied spaces in combination with Annual Sunlight Exposure (ASE), replacing the fixed upper boundary of UDI by an indicator of direct sun penetration into the occupied space. IES definition of ASE is "the percent of an analysis area that exceeds a specified direct sunlight illuminance level more than a specified 
number of hours per year." [8]. By all means, it is an indicator for visual discomfort and the amount of direct sunlight which hits the workplane in the whole year.

The most initial and relevant concern which is analyzed here has become the window design; since, the opening characterization determines the amount of daylight penetration and the path of its distribution inside the room. The basic design indicator to denote its performance is window-to-wall-ratio (WWR). It is an instructive parameter in making design decisions due to its numerical simplicity but its complexity in extracting thermal, visual and environmental consequences/or information in architectural design. The impact of window geometry and methods to optimize window size and optical properties of glazing for thermal and visual performance have been demonstrated using computational simulation [9-13].

Complex Fenestration Systems (CFS) enhance the daylight performance of buildings. Redirecting daylight from the often overexposed building perimeter deeper into the occupied space, they reduce discomfort close to the façade and distribute daylight evenly. The technology allows substituting artificial lighting by daylight even in deep plan buildings [14]. The integration of such systems' within the façade has been identified as a major obstacle to wide-spread application. The miniaturization and integration into double glazing units of CFS such as micro-prism films (MPF) and acrylic lamellas address this challenge and ease both installation and maintenance, and allow applications in building retrofits. MPF are assemblies composed of micro structured prisms on an optical film. The performance of such systems for the case of side-lit spaces has been compared through simulations and monitoring of experimental setups [15-18].

The optical characterization of a CFS and conversion into models for use in Radiance [19-21] are further research areas. Previous studies involved measurements of the optical properties of CFS using specialized instruments in laboratories [22,23], using virtual instruments [24] and their integration in performance assessments [25]. Measurements display their behavior in refracting, reflecting and redirecting the light at certain angles. That outcome is called the Bidirectional Scattering Distribution Function (BSDF) data. This is a kind of indicator which quantifies how light scatters as a function of light incident direction. This concept involves reflection and transmission distributions on any type of materials (specular, non-specular). Several experimental studies and recent approaches deal with its use in the field of daylight performance and its integration in daylight simulations [19-21].

In view of the recent and ongoing research mentioned above, evaluations about the application details and performance of CFS have been continuous broadly, however, it is also necessary to widen the research to relate their design, function and integration to architectural considerations, one of which is specifically is the window design in this study. Thus, the optimization problem, here, is to achieve the necessary MPF area while minimizing WWR to meet the required sDA value which is $75 \%$ (denoted as preferred value by IES). In this case, obtaining essential MPF area means to reach the minimum film-to-window ratio (FWR). This is a case study which covers design alternatives of the glazed area with the integration of MPF. Specifically, the case room is typically has large window area (WWR is 75\%) and the floor aspect ratio is almost 1 . The daylit area is satisfactorily large but may cause discomfort glare and overheating. So, it may be necessary to improve daylight performance and environmental conditions with the application of MPF in window area. Utilizing such integration, it is crucial to find the minimum size of the glazing area to satisfy the $75 \%$ of sDA in the city of Lucerne, Switzerland. This study involved discussions about the design variants of MPF size to be mounted in the fenestration in a specific location and under sky/climatic conditions in Lucerne. The main performance indicator is sDA. However, to compare findings between variants and to construct a deep and full understanding of MPF performance, ASE, msDA (monthly daylight autonomy) and MSE (monthly sunlight exposure) were assessed. The application of dynamic sunshade in simulations provided avoidance of direct sunlight due to climate data. The outcome of this was the percentage of sunshade operation during the year. To test the
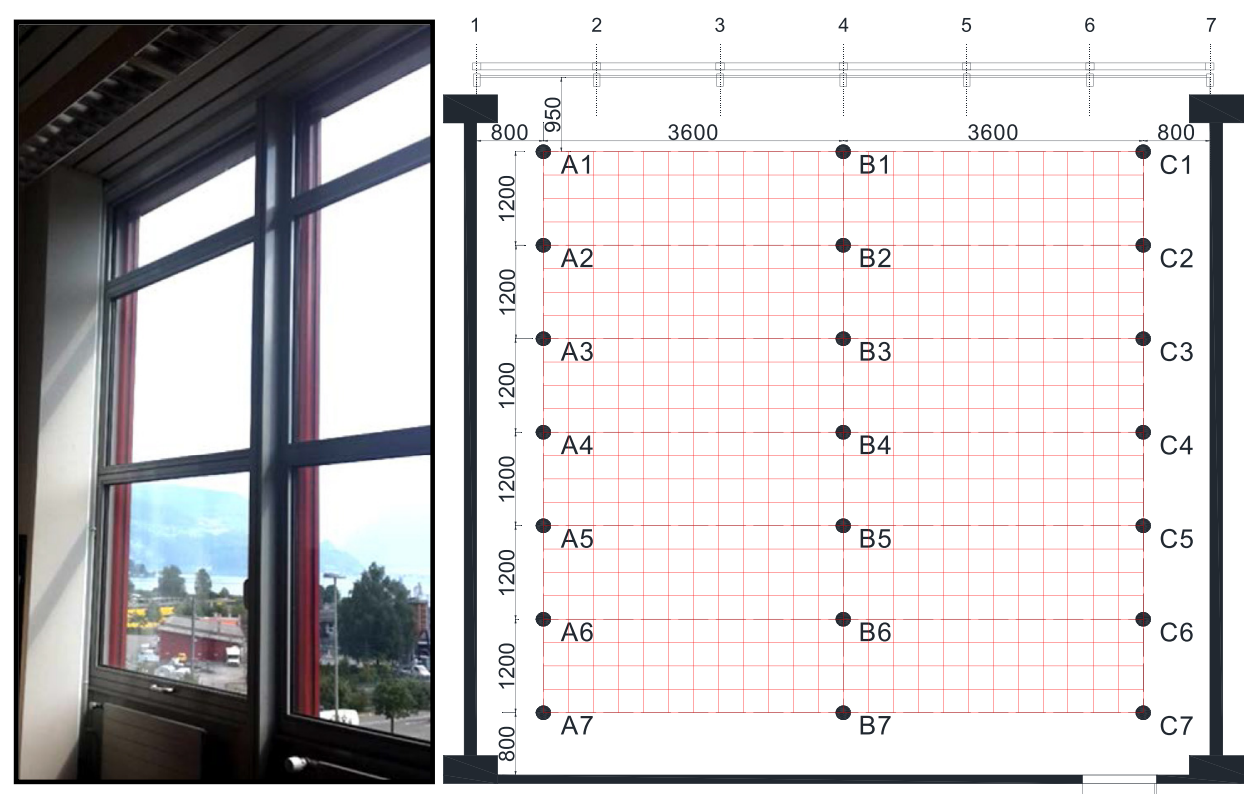

(a)

(b)

Fig. 1. (a) Window configuration; (b) Measurement points and sensor plane (the red grid). (For interpretation of the references to color in this figure legend, the reader is referred to the web version of this article.) 


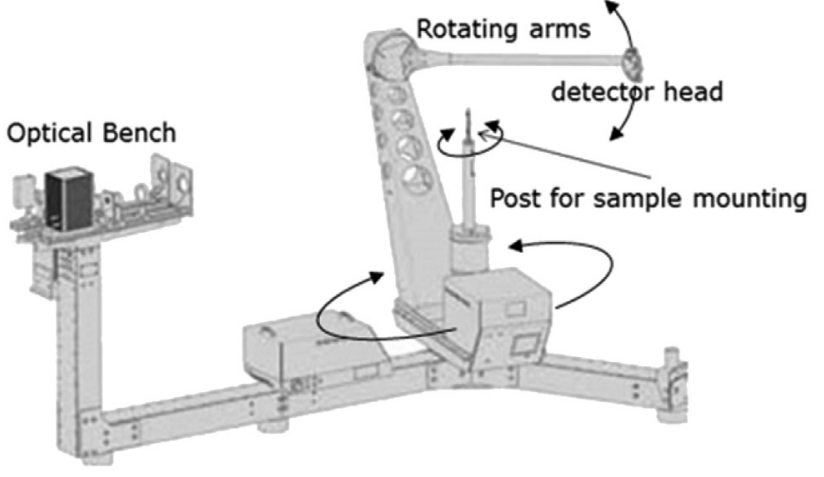

(a)

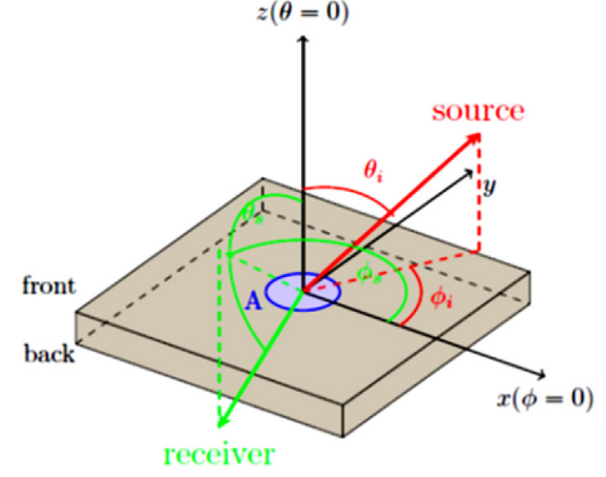

(b)

Fig. 2. (a) Sketch of a goniophotometer; (b) Transmissive sample with source direction $\left(\theta_{\mathrm{i}} ; \phi_{\mathrm{i}}\right)$, receiver direction $\left(\theta_{\mathrm{s}}\right.$; $\left.\phi_{\mathrm{s}}\right)$ and sampling aperture A.

film's performance annually, it might be possible to reach valuable design information about the most appropriate way of using MPF within a glazed area for such rooms.

\section{Experimental set-up}

\subsection{Description of the case room}

The case room (classroom for students of architecture) is located on the second floor of a building of the Lucerne University of Applied Sciences and Arts, Switzerland. The building is situated in a campus, in Lucerne (latitude $47^{\circ} 0^{\prime} \mathrm{N}$; longitude $8^{\circ} 18^{\prime} \mathrm{E}$ ) at an altitude of approx. $436.00 \mathrm{~m}$ over sea-level. The campus is about $5 \mathrm{~km}$ South of Lucerne. The climate of the city can be identified as cool-humid according to ASHRAE International Climate Zone Definitions [26]. The room facing South is approx. $80 \mathrm{~m}^{2}$ $(9.05 \times 8.80 \mathrm{~m})$ and its story height is $3.60 \mathrm{~m}$. The actual window configuration and the room's basic layout are shown in Fig. 1.

\subsection{On-site measurements}

Illuminance and spectral measurements were taken at varying hours during the days from August 11 to August 14, 2015, under clear, intermediate and overcast sky condition.

The measurement procedure was based on recommendations

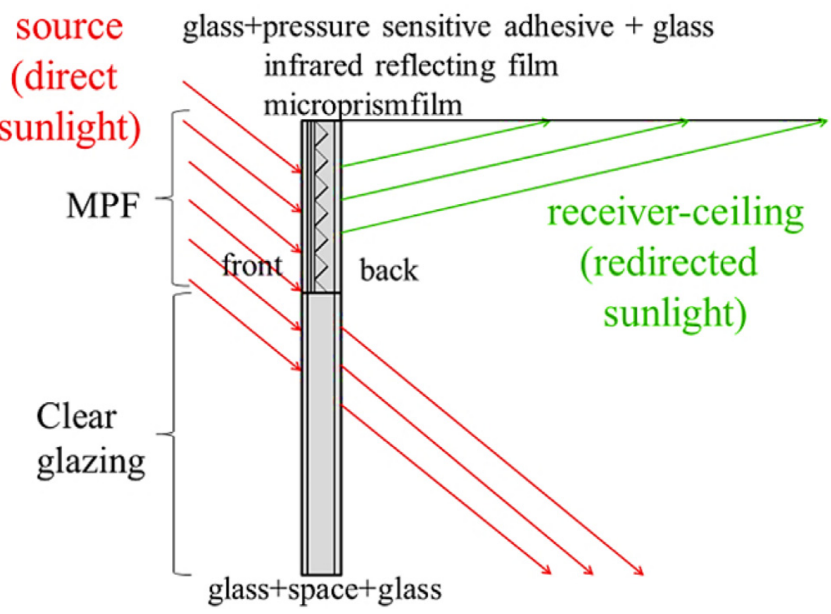

Fig. 3. Schematic section of a MPF and daylight redirection. and experience in accordance with IES and previous studies [8,27-29]. First, it included measurements of horizontal work plane illuminance using a radiometer/photometer with a silicon detector attached by a flexible cable. The detector is fixed on a tripod to satisfy a constant height which is $0.95 \mathrm{~m}$ from the floor level. This is higher than the recommended ones $(0.75 \mathrm{~m})$ but is specifically in accordance with the desk-height inside the room. The number of measurement points is based on daylighted zones and distance from the windows [29]. "A large classroom may require three zones, with three test points at each zone to represent illuminance at the front, middle, and on the back of the classroom" [29]. However, to increase the accuracy, the requirements of IES about analysis points in simulations are additionally followed. Thus, spacings of measurement points are multiplications of $0.60 \mathrm{~m}$ as IES suggests a "two-foot analysis grid" [8]. Measurement points match the sensor grid (Fig. 1b) which is centered on the workplane. To capture daylight illuminance variations across the room, points are aligned more densely through the room depth. So, the grid is taken $0.80 \mathrm{~m}$ away from walls and a total of 21 measurement points are displayed in Fig. 1b.

The solar conditions are obtained from a local pyranometer-solar measurement station, which is mounted on the roof of the case building. It records averaged global (GHI_Avg in W/ $\mathrm{m}^{2}$ ) and diffuse horizontal irradiance (DHI_Avg in $\mathrm{W} / \mathrm{m}^{2}$ ) in one minute intervals.

Second, this procedure involved spectral measurements of reflected light from a surface material using spectrophotometer. They provided the remission spectrum of a sample which was embedded in the daylight simulation model to identify the surface spectral reflectance. The device is connected to a separate probe using a flexible cable and operates with software to collect and store the sample data in the computer. The measurements were taken on wall, floor, ceiling, desk, shelves and window frames. The glazing transmissivity (0.85) is calculated and is based on the transmission of a typical double glazing unit (0.78) taken from the International Glazing Database IGDB [30]. The IGDB in conjunction with LBL Window 7, which has a recent release of the DB integrated, is used [31].

\subsection{BSDF measurements}

The instrument which measures BSDF data is called the scanning goniophotometer whose extensive use and its operational capabilities also, are cited in literature [32-34]. The measurement process follows similar approaches in the previous studies [22-24] and recommendations in the standard [35]. The goniophotometer 


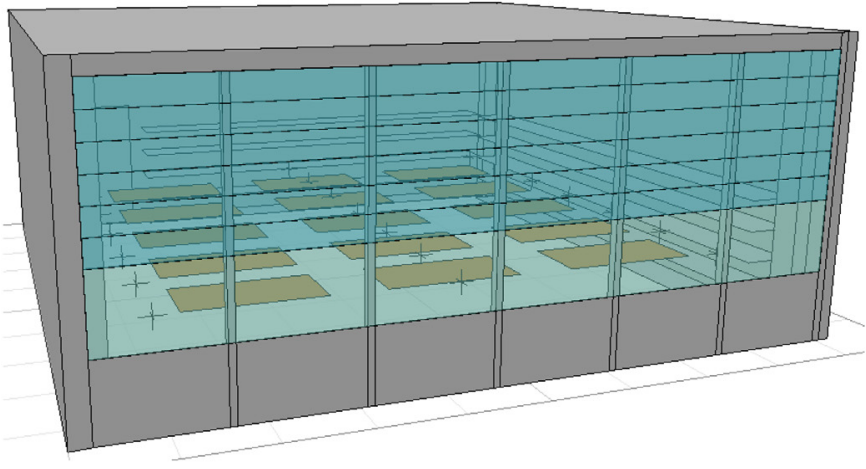

(a)

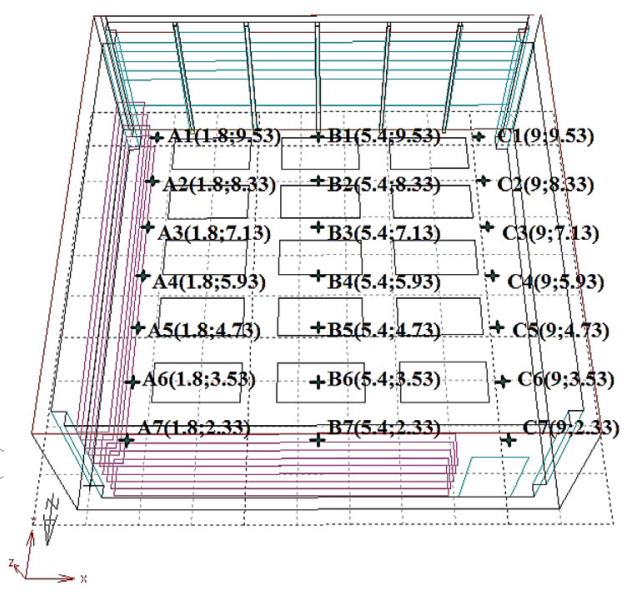

(b)

Fig. 4. (a) Geometry of the model for the optimization; (b) Distribution and 2D coordinates of the points.

Table 1

Reflectance spectrum at $700 \mathrm{~nm}$, obtained from surfaces on-site.

\begin{tabular}{llllll}
\hline Wall & Ceiling & Floor & Desk & Shelf & Window frame \\
\hline 0.88 & 0.85 & 0.18 & 0.51 & 0.53 & 0.46 \\
\hline
\end{tabular}

has three main parts; the light source (source), the sample holder and the detector (receiver) [32](Fig. 2a). To avoid stray light, it is located in a dark room. A baffle made of anodized metal separates the light source (a halogen lamp or a xenon lamp) and an optical bench from measurement area. The sample holder and the detector are behind the baffle in the dark room. A hole inside the baffle allows the passage of light beam to that side. The sample with a size up to $1.00 \mathrm{~m}$ by $1.00 \mathrm{~m}$ can be placed in the sample holder defining the $0^{0}$ orientation. The sample holder is rotated in its y-axis to determine $\theta$-angles (corresponding to the altitude) using remote control, while it is necessary to rotate in its x-axis (that is the normal line of its flat surface) to set $\phi$-angles (corresponding to the azimuth) by hand. These rotation angles are marked on the holder for the ease of use and precision. Fig. $2 \mathrm{~b}$ is the $3 \mathrm{D}$ representation

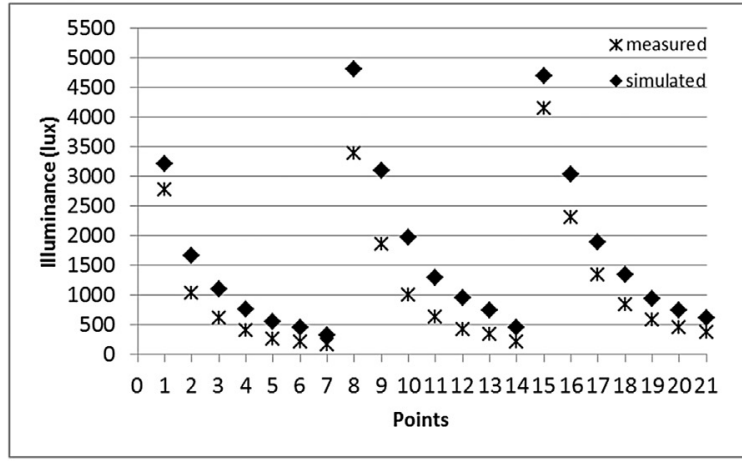

(a)

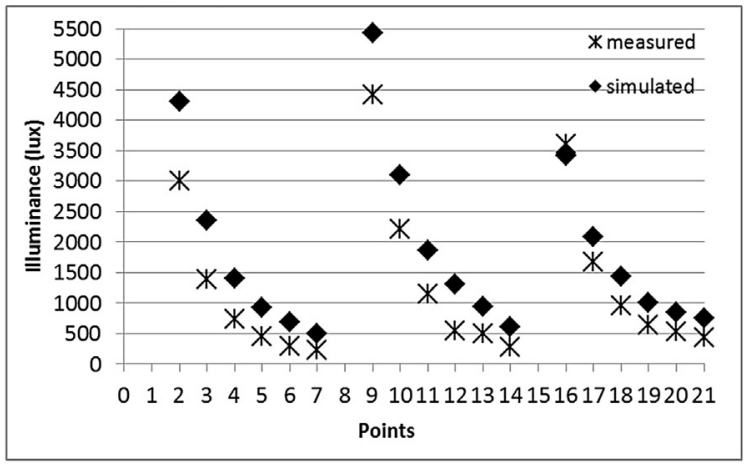

(c)

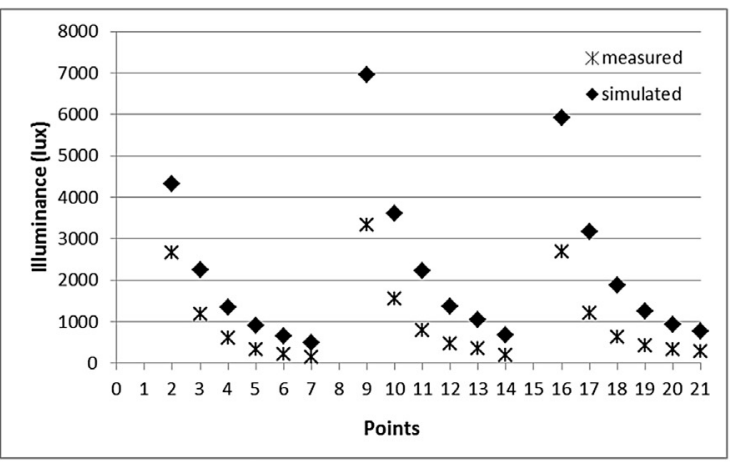

(b)

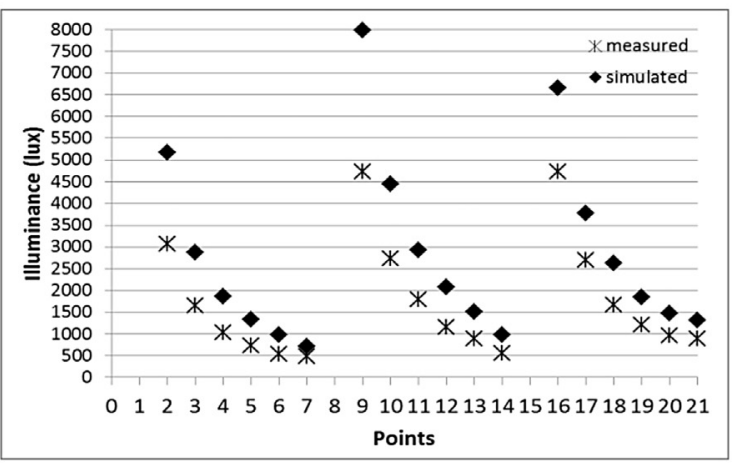

(d)

Fig. 5. Comparison of measured and simulated results for (a) a sunny, (b) a cloudy (c) and (d) partly cloudy days. 


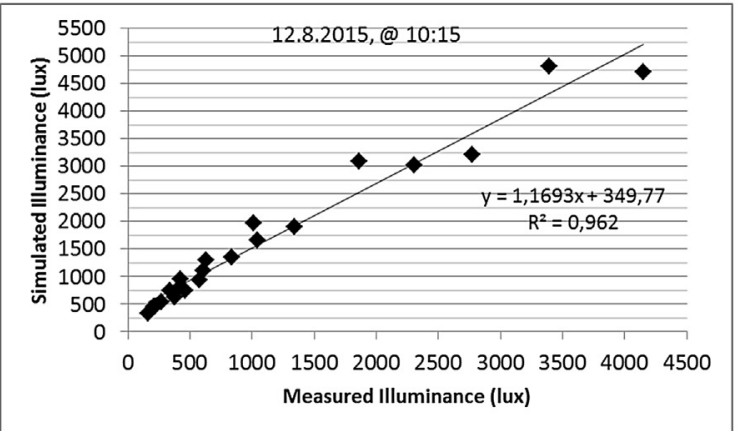

(a)

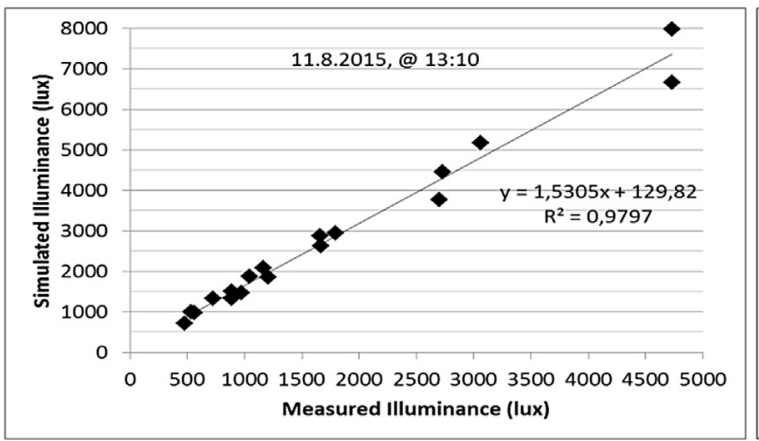

(c)

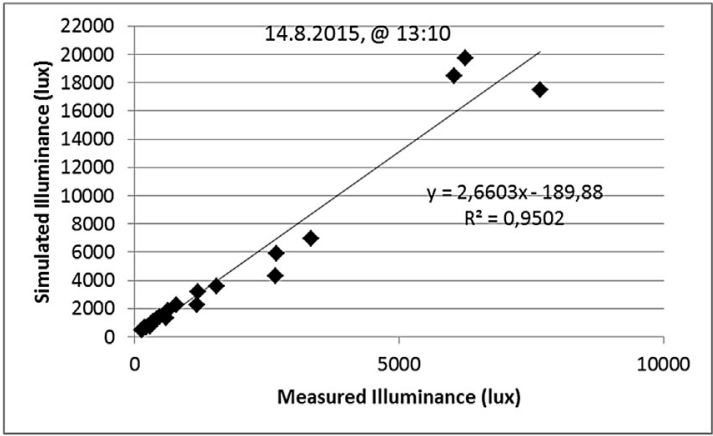

(b)

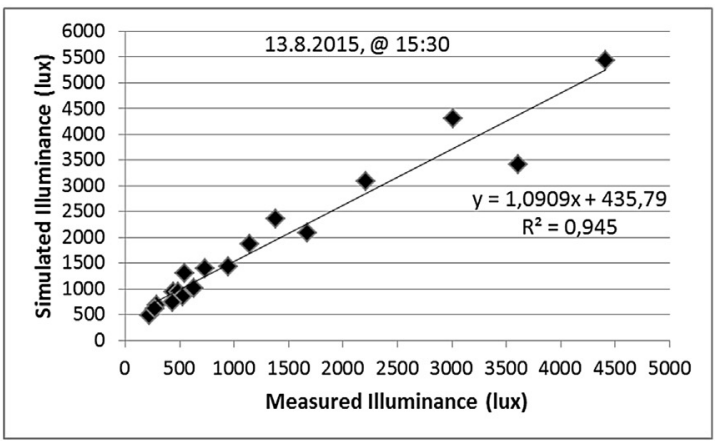

(d)

Fig. 6. Correlations between measured and simulated results for (a) a sunny, (b) a cloudy, (c) and (d) partly cloudy days.

displaying how light is transmitted on the sample surface with designated angles.

The detector head is connected to the sample holder and rotates around it inside a virtual sphere to capture the light beams which are reflected and transmitted, when the light beam hits the sample. The back part of the sample holder is the transmittance hemisphere and the front is the reflectance hemisphere. The head focuses on a certain region, in this sphere, where the density of light beams is concentrated according to the incident angle. The software performs the remote control separately. The light source, a halogen lamp, is switched on. The incident angles and the choice of detector are set using the software; the measurements performed. The number of runs which the detector scans the hemisphere depends on the resolution. The smallest the light beam, the highest the resolution. In higher resolutions, it has higher peaks. The air temperature of the environment is controlled and set to $23{ }^{\circ} \mathrm{C}$ to achieve appropriate measurements. The outputs are the numerical data and graphical representation of light-rays-mapping in a virtual hemisphere for each angle. A reference measurement is also performed without the sample at the end of the measurement sessions, as recommended in a previous study.

In this study, a total of 30 set of measurements were performed. The $\theta$-angles which indicate the incidence directions are $0^{\circ}, 15^{\circ}$, $30^{\circ}, 45^{\circ}, 60^{\circ}$ and $65^{\circ}$. The $\varphi$-angles are $0^{\circ}, 45^{\circ}, 90^{\circ}, 135^{\circ}$ and $180^{\circ}$. The diameter of the light spot caused by the light beam on the sample, when it is mounted on its $0^{\circ}$ orientation, is approx. $35-40 \mathrm{~mm}$. The sample is a light redirecting film which is composed of micro-structured prisms attached on an optical film

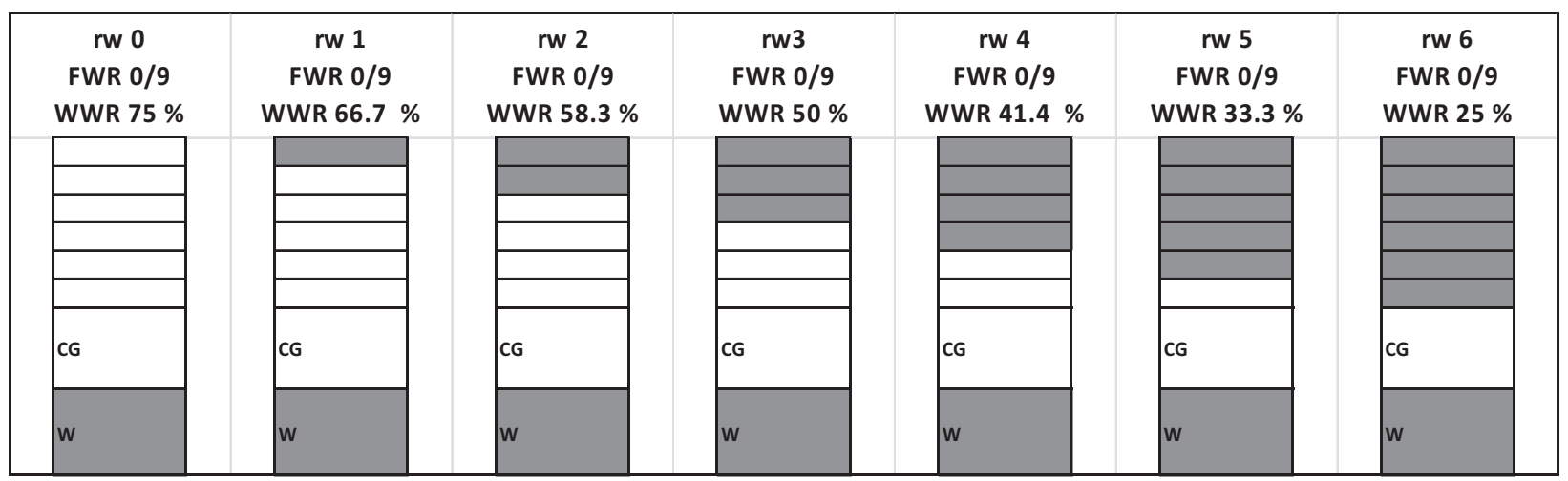

Fig. 7. Schematic views of window variants in the first optimization approach (rw: regular wall; CG: clear glazing; W: wall). 


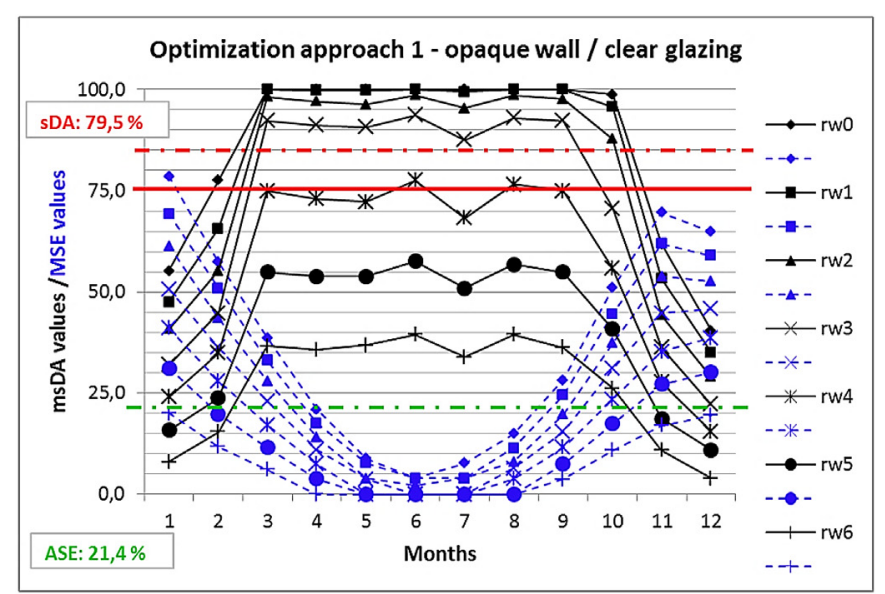

(a)

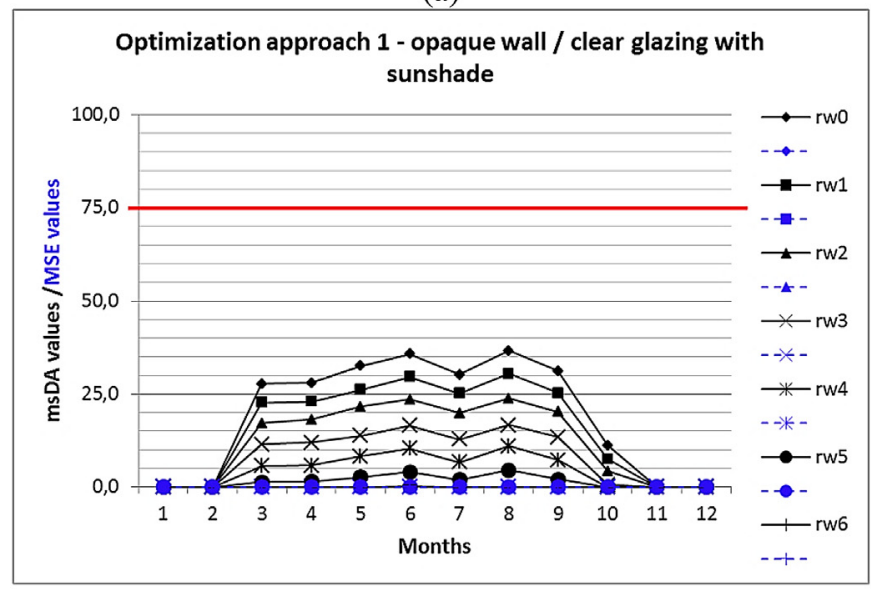

(b)

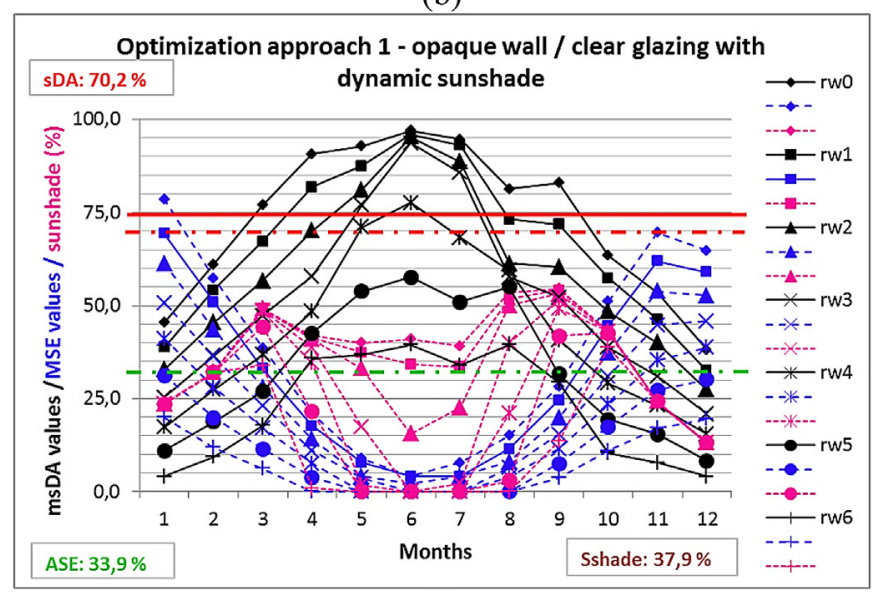

(c)

Fig. 8. Monthly breakdown of sDA for each window variant with clear glazing and opaque wall material.

(Fig. 3) and named as micro-prism film (MPF). They are aligned between two glass panes to redirect/refract daylight to the ceiling and to provide transmission of light deeper in the buildings. Its thickness is approx. 300 microns. It is also used as a sun shading device. Such weaknesses found out in previous studies are their inefficient performance under overcast sky conditions, or on north facades or obstructed windows; and reducing the view to the outside. However, its strength is its efficient use in the upper part of the window when it receives direct sunlight $[16,36]$.

\section{Simulation model construction}

\subsection{Geometric model}

A geometric model of the case room was created using Ecotect (Fig. 4a). Dimensions were taken from architectural drawings and on-site measurements. The units were set in millimeters. The existing room was arranged, as one zone including glazed openings with gray aluminum frames and furniture, to be used as the actual room model. Another geometric model was employed excluding the frames and composing the window area into segments, to be used as the optimization model. Each segment's height is $0.30 \mathrm{~m}$. Inner surfaces of the room, desks, shelves, window, frames and measurement points were set in separate layers. Furniture layout was modeled with equal spacing regularly as recommended in the IES standard [8]. Descriptive surface names were chosen for each layer to allow the implementation of material identifications in the following simulations. The geometry was exported to Radiance Scene file (as the .rad-format).

\subsection{Reflection and transmission based on analytical BSDF models}

The Ward-Dür reflection model as implemented in the plastic and metal material classes of Radiance describes reflection based on reflectance (separately for three color channels RGB), specularity and roughness [37]. Specularity and roughness were set to zero for the predominantly diffuse reflecting surfaces, only for the window frames these values were estimated. Three reflectance values for each sample were derived from on-site measurements using a spectrophotometer.

The spectrophotometer used in this research records the remission spectrum of a sample relative to a standard with a highly reflective Barium Sulfate coating for wavelengths from $400 \mathrm{~nm}$ to $700 \mathrm{~nm}$ in $5 \mathrm{~nm}$ intervals (Table 1). As the exact reflection spectrum of this standard is unknown, but can be expected to be higher than 0.96 in the considered wavelength range according to measurement of comparable coatings, the remission spectra were used in place of reflection spectra in the later calculations [38,39]. Color calculations are defined for a range from $380 \mathrm{~nm}$ to $780 \mathrm{~nm}$, exceeding the range of the measurements. To achieve a basic extrapolation covering the full range up to $780 \mathrm{~nm}$, and to provide a linear interpolation for wavelength in between the measured intervals, the tabular remission spectra were translated into functional descriptions using the Radiance command tabfunc.

Based on these approximations, the $\mathrm{XYZ}$ tristimulus values for each sample under an equal-energy illuminant (CIE illuminant E) were calculated for a CIE $19312^{\circ}$ observer [40-42]. The conversion of the tristimulus values to the expected RGB color triplets was achieved making use of the script xyz_rgb.cal as provided with Radiance.

As the spectrophotometer configuration limits its application to reflection measurements, the existing double-glazing had to be modeled based on values from literature. A center-of-glass transmittance of 0.78 was assumed for the visible light range, based on a typical double-glazing unit from the International Glazing Database IGDB. Radiance provides an optimized model for thin glass panes, allowing to model the glazing without a thickness by its transmissivity, which was calculated from transmittance $[30,31]$.

\subsection{Data-driven BSDF model of daylight redirecting glazing}

The irregular transmission characteristics of the daylight redirecting film applied in the study cannot be modeled as the transmission model for glass in Radiance. For redirecting, prismatic structures, two models for off-specular peaks exist with prism and 
prism2. However, both models imply limitations in the number and distribution of peaks, and cannot describe the diffuse transmission through the film. A recent addition to Radiance introduces a compact data-driven BSDF model, which is based on measured data and can represent virtually any possible, irregular BSDF for both transmission and reflection. The data-driven model reads a compact tensor tree from a xml-file and is fully supported in both the deterministic and the stochastic light transport algorithms. The tensor tree can be generated either from computed BSDF data, e.g. using the Radiance command genBSDF, or by interpolation from measured BSDF datasets [37].

The data-driven model was developed to represent daylighting devices with irregular BSDF. These typically comprise complex features such as peaks and rims, which need to be captured by the measurement in sufficient detail. One strategy for the measurement of such distributions is based on an asymmetric directional resolution of incident source directions and outgoing receiver directions. The characteristic features are highly resolved by scanning at high resolution for each incident source direction, leading to typically records for $100,000-200,000$ receiver directions per source direction. As it is assumed that these features do not rapidly change when the source direction is varied, but rather get translated and blended, the number of incident source directions is kept low. The construction of a complete representation of the BSDF from the coarse set of this asymmetric measurement thus requires an interpolation algorithm maintaining the features and physical plausibility for any combination of source and receiver directions. Two commands in Radiance provide this functionality by implementing a mass-mover interpolation algorithm. First, the measured, discrete distributions are replaced by Gaussian interpolants. Second, the interpolants are sampled at a given resolution, leading to a discrete tensor tree representation of the BSDF. Third, a data-reduction algorithm is applied to locally adapt the resolution of the tensor tree to the variance found in the distribution. The compact tensor tree is then, annotated with meta-data from the measurement, written to an $\mathrm{xml}$ file that can be read by a variety of software tools.

\subsection{Measurement points and sensor plane}

As the geometry of the room is exported from Ecotect into the Radiance scene file (.rad file), the location of the measurement points are determined due to the origin in Ecotect file. Radiance applied the right-hand Cartesian coordinate system [37] based on that origin and located the points (Fig. 4b). The numbers designate the distances in meters from the perpendicular lines ( $\mathrm{x}$-axis and $\mathrm{y}$ axis) according to the origin as shown in Fig. $4 \mathrm{~b}$. They are used to compare the illuminance read in the measurements and the values in Radiance model of the actual room. However, a new sensor plane (Fig. 2) was generated in $0.30 \times 0.30 \mathrm{~m}$ resolution including a total of 625 calculation points $(25 \times 25)$ for the further optimization process. This sensor plane was at $0.95 \mathrm{~m}$ height as it was in the actual model.

\subsection{Setup of simulation environment using EvalDRC}

EvalDRC (Evaluate Daylight Redirection Components) is a software to run annual daylight simulations based on Radiance daylight coefficient calculation with Enhanced Photon Mapping $[43,44]$. The inputs are Tregenza sky model for the hemispherical sky radiance distributions, Perez sky model with actual climate data for sky/sun patch radiances, a Radiance scene including geometry of the room, micro-prism film, sensor points, and processing parameters including time, location, metric boundary values and Enhanced Photon Mapping and renderings etc. The significance of this tool is based on its definition of a separate sky patch and sun contribution patches to locate the sun as a direct light source on the hemisphere as it is in reality. The first step of this process is to configure the sky while determining cumulative sun primitives as separate $0.5^{0}$ RADIANCE source primitives. The software completes this step with the inclusion and identification of sky patch and solar radiance distributions due to the location and time. The second step is to calculate the position of primary photons according to the path from the light source; to contribute each photon on the surface as the light sources and to evaluate their contribution by a modified photon density estimate on another surface which is named as the generation of photon maps. A simultaneous calculation is employed for the separate sky patch and sun contribution coefficients. The third step is to accumulate the scaled coefficients to get the illuminance values and HDR renderings. Finally, the reduction step is implemented to generate characteristic parameters of the daylight performance in the model.

Outputs are illuminance, HDR images and sDA as defined by IES. To employ the Enhanced Photon Mapping, photon ports are modeled for all openings; virtual photon receivers overlay the sensor point grid to collect the caustic photons around the sensor; contribution photons are used to calculate multiple sun positions simultaneously; different illuminance distribution characteristics call for separate sky and solar photon maps to avoid noise in sky contributions near sunlit areas [45-47].

In this study, the Radiance scene generated from Ecotect optimization model (Fig. 1b) was run by EvalDRC. A photon port and a sensor plane were located in front of the window area and above the measurement points. The Perez sky model based on weather data for Geneva, Switzerland was employed in the calculation process.

\subsection{Configurations of façade systems}

The façade of the geometric model (Fig. 4) is composed of one clear glazing segment which is $0.90 \mathrm{~m}$ high, six clear glazing segments each of which are $0.30 \mathrm{~m}$ high and an opaque wall area of $0.90 \mathrm{~m}$ high. Three optimization approaches were proposed to acquire the minimum WWR and MPF. The largest segment of clear glazing in the middle zone and the wall area below has been identical as in the base model. The first approach involves changing the segments of clear glazing in the upper zone to opaque wall as one by one row, starting at top. The second approach follows a similar procedure; however, clear-glazed segments are set to be micro-prism film (MPF). The third optimization approach, which is the combination of previous ones, defines the replacement of MPF segments with opaque wall segments. The performance indicator is SDA; while the others are ASE, msDA and MSE values. The required SDA is $75 \%$ as the preferred value regarding IES. Illuminance threshold is set as 500 lux which is recommended for a classroom [48]. As the illuminance is the primary daylight metric, illuminance plots at midline across the room are used for complementing sDA results in understanding the daylight distribution and uniformity inside the room at specific timestamps (i.e. solstices, equinoxes) in detail. As UDI defines the upper threshold values unlike sDA, it is possible to analyze and discuss how illuminance fluctuates within the UDI range (500-2000lx); and whether excessive daylight values occur at any particular regions in the room or not. False color illuminance maps assist to present whether the daylight distribution is differentiated or not, applying the identical MPF area at dissimilar positions in two window configurations. 


\section{Data analysis}

\subsection{Comparison of measurements and radiance findings}

The comparison of actual daylight illuminance with the simulated ones showed that the simulation outputs were higher than the measurement ones (Fig. 5). The first row which is located beyond $1 \mathrm{~m}$ from the windows directly denotes the impact of transmittance of the glazing under direct sunlight; so, the RE between the Radiance outputs and the measured ones ranged from $13 \%$ to $42 \%$ in the sunny day. Linear regression analysis allowed estimating the relationship between the on-site measurements and simulation results. The coefficient of determination $\left(R^{2}\right)$ values were approx. 94\%-97\% for the sunny and cloudy days; showing the high accuracy of the simulation model (Fig. 6). Despite these high correlation rates, the simulated outputs were two times higher than the measured ones on the first row near the window in the cloudy day. Such an expected finding is supposed to be caused by the scattered pattern of clouds. The normalized-root-mean-squaredeviations were calculated to compare these two data sets as below (1). The very low values of approx. 0.03 indicated very low residual variance.

$N R M S D=\frac{R M S D}{y_{\max }-y_{\min }}$

where NRMSD is the normalized-root-mean-square-deviations, $R M S D$ is the root-mean-square-deviations, $y_{\max }$ is maximum value of the data and $y_{\min }$ is the minimum value of the data.

\subsection{Optimization of window size using EvalDRC}

\subsubsection{The first optimization approach}

The first approach, which remains to be a regular window design, is demonstrated to understand how the reduction of clear glazing would result in varying daylight conditions and how much of WWR would be decreased to reach the desired visual circumstances according to the required IES quantities mentioned in above section. Segments in the upper glazing are set as one by one row from clear glazing to opaque wall, starting at top (rw0-rw6 in Fig. 7). It is known that sunshades are commonly preferred to avoid sun patch which disturbs vision. To correspond to the reality, the next step is to apply a static sunshade to cover clear glazing area. The sunshade is generated with a visible diffuse light transmission of $10 \%$ which means that it blocks direct sunlight at any incident angle. A further application of a dynamic sunshade with on/off operations excluded the redundant use of the static one, considering annual climate data. A practical consequence of this dynamic integration avoids the unnecessary use of sunshade in overcast days. Such simulations provided the percentage of sunshade operation (Sshade) in the whole year.

Fig. 8 illustrates monthly breakdown of sDA, MSE and Sshade values derived from the first set of EvalDRC simulations. These findings are due no-sunshade, with static-sunshade and dynamicsunshade conditions. Each graphical representation depicts the quantity of sDA, ASE, and Sshade for the optimal window composition. The majority of the window variants except rw4, rw5, rw6, satisfy the sDA of $75 \%$, when there is no sunshade. The regular window with 50\% WWR (rw3) meets that required value initially, resulting in $79.5 \%$ sDA. When the WWR is reduced from $75 \%$ to $50 \%$, a reasonable decline in ASE is observed (from 34\% to 21\%), meaning that, a 33\% fall in WWR is proportionate to the decrease in ASE. The nature of designing window geometry reduces solar heat gain and results in less necessary shading.

On the contrary, none of the variants is successful in passing the threshold sDA value when there is static sunshade. The values remain very close to zero. The sun shade operation has extreme effect on sDA values and completely blocks daylight when rw4, rw5, and rw6 are modeled ( $0-1 \%$ sDA).

When dynamic sunshade is active, even the variant with the largest window size (rw0-the existing façade) causing 70\% sDA fails to reach the preferred criterion. In this case, reducing $75 \%$ WWR to $50 \%$ WWR leads to a $20 \%$ reduction in sDA, meaning that, sDA of rw3 is $52 \%$. Implementing dynamic sunshade has become the reason of considerable declination in sDA, i.e. $79.5 \%$ sDA of rw3 without sunshade has turned to be $52 \%$ with an active sunshade. In addition, $30 \%$ of reduction in sDA (from $99.8 \%$ to $70.2 \%$ ) is observed when the dynamic sunshade controls the existing façade composition (rw0). The ASE range remains similar to the non-shade compositions. sShade varied from $37.9 \%$ to $14.9 \%$, meaning that, shading operation is necessary during one third of the year when $75 \%$ WWR is considered. Consequently, the existing facade with the regular window cannot yet be able to satisfy sufficient daylight conditions in the whole year.

\subsubsection{The second optimization approach}

The largest segment of clear glazing and the wall area are fixed identically in the base model. Segments in the upper glazing are set as one by one row from clear glazing to microprism film (MPF), starting at top (drc0-drc6 in Fig. 9). As the 75\% WWR is identical for each design variant, the objective is to figure out the possible minimum film-to-window ratio (FWR).

Fig. 10 presents the findings derived from the second approach in detail. The predominant finding here is the strong effect of MPF in every window case, when compared to the previous approach.

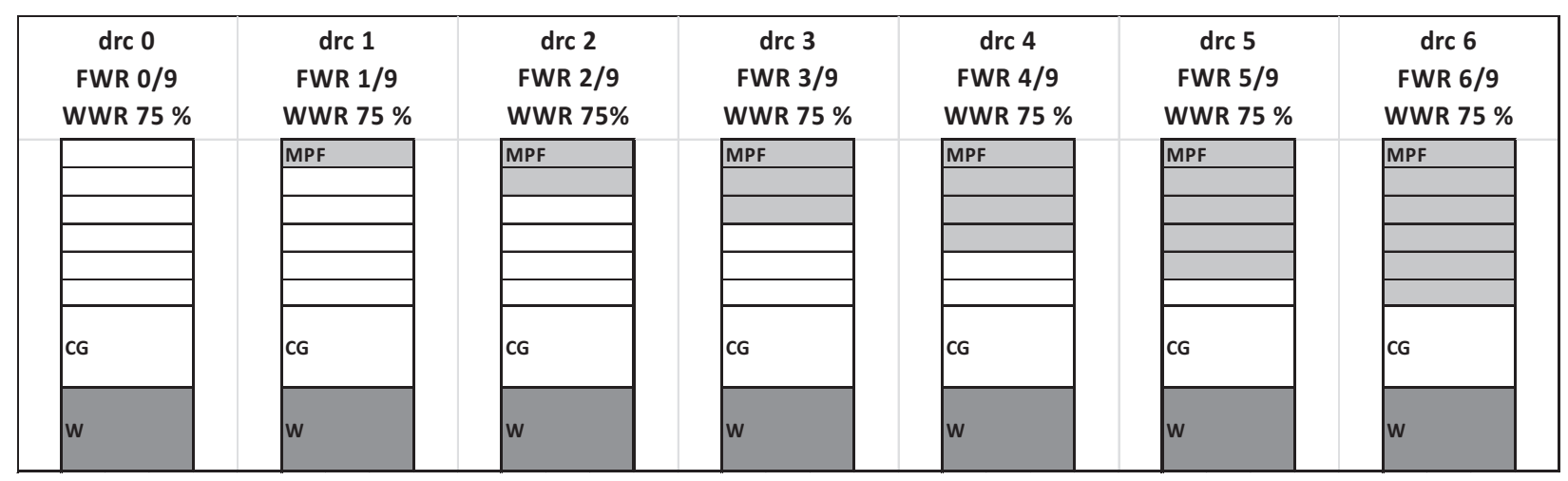

Fig. 9. Schematic views of window variants in the second optimization approach (drc: daylight redirecting component; MPF: microprism film; CG: clear glazing; W: wall). 


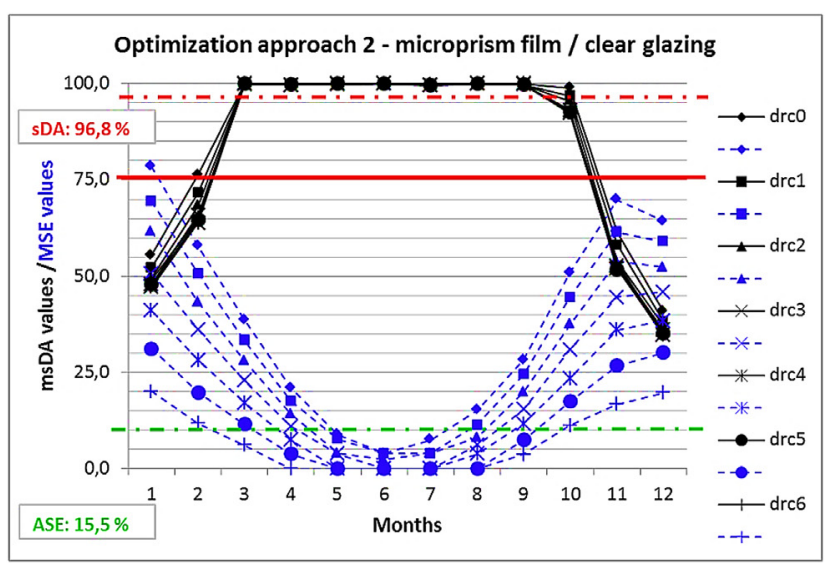

(a)

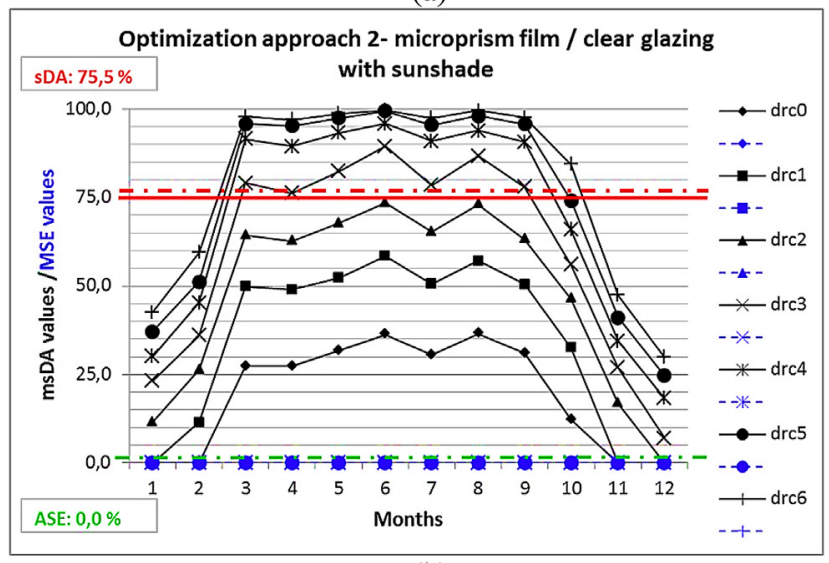

(b)

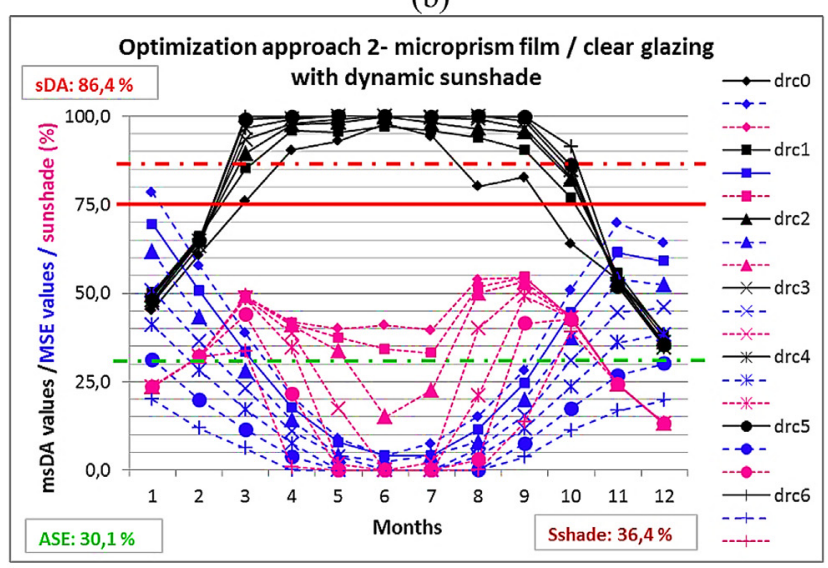

(c)

Fig. 10. Monthly breakdown of sDA for each window variant of micro-prism film and clear glazing (a) without sunshade; (b) with sunshade; (c) with dynamic sunshade.
The rise in SDA and msDA is clearly apparent in both non-shaded and shaded conditions as in Fig. 10a-c. For example, the rate of improvement in sDA is approx. $130 \%$ for rw4 (42.2\% sDA) when converted to the variant drc4 (96.8\% sDA) including MPF.

All window variants are extremely above the sDA of $75 \%$ (i.e. drc4 with $96.8 \%$ sDA and $15.5 \%$ ASE). Although the majority of them reached to a msDA of $100 \%$ over the whole year, they failed to satisfy the requirement in winter time (November, December, January and February). Even, they never meet the msDA of 50\% (satisfied value by IES) in December. The ASE rate is less, when compared to the first approach. Its distribution however, is similar to the previous optimization findings as a consequence of similar height of clear glazed segments in both optimization cases.

The impact of the sunshade is dramatic; since only one segment of film (drc1) remaining open if the rest of the window area is covered by sunshade, already makes a big difference in daylight illumination. Converting the regular window variant rw1 into a film-glazed variant drc1 leads to a change in sDA of $15 \%$ into $40 \%$, depicting an improvement of approx. 160\%.

The impact of avoidance of direct sun light on daylight performance is strongly obvious when compared to the non-shaded composition (Fig. 10b). The variant drc4 with 4/9 FWR passes $75 \%$ sDA firstly and has got $15.5 \%$ ASE, when static shade is performed The sun shade operation has rather little to almost no effect on SDA values, if the MPF area is high, i.e. 4 or more segments covered with film. This reveals the shading behavior and high effectiveness of the film as well. Its shading characterization remains valid in this study. Such variants (drc3-6) meet the sDA of $75 \%$ for the majority of the months and the year. ASE of zero indicates the full protection against sunlight as a means of solar gain and visual discomfort.

Though, dynamic sunshade improved the sDA values for all variants, the sDA curves become closer and higher as in Fig. 9c. The rate of sunshade operation ranged from 14.9 to $38.4 \%$ annually, while the ASE values varied from 5.4 to $33.9 \%$ reversely. It is noticeable that the variant with one segment of MPF (drc1-86.4\% sDA) with dynamic sunshade satisfied the daylight performance criterion initially when compared to others, although each variant has identical WWR of $75 \%$. Thus, we realized how the application of only FWR of $1 / 9$ caused the rise in SDA (from $69.6 \%$ in drc0 to $86.4 \%$ in drc1) to pass the requirement. The further step which is a combination of previous two approaches requires the modifications of WWR to get the minimum fractions as well as of FWR within the window variants.

\subsubsection{The third optimization approach}

This section describes the approach which is based on the composition of MPF and wall segments in the upper window. The film segments in drc6 in Fig. 9 were replaced with the wall material step by step, similarly to configure MPF-to-wall variants (w0-w6)

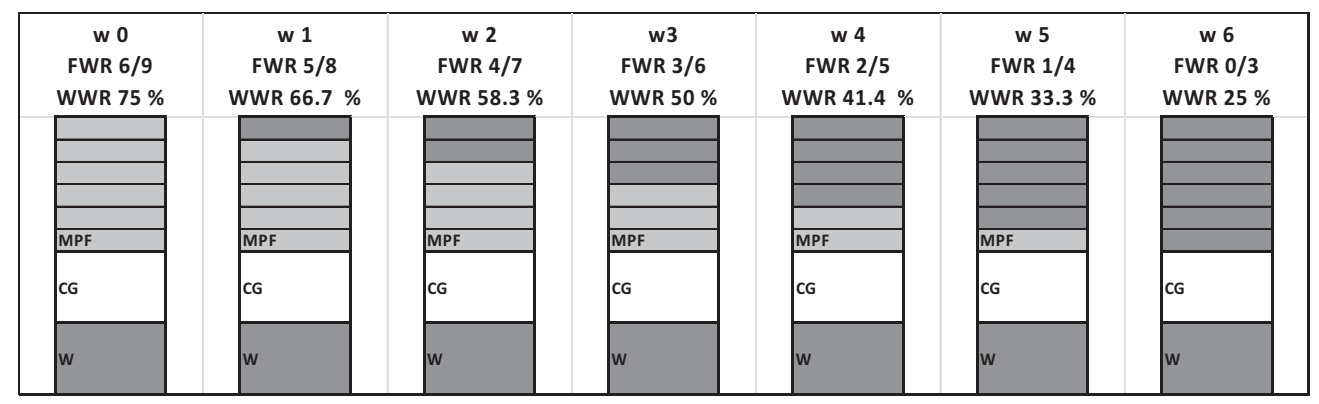

Fig. 11. Schematic views of window variants in the second optimization approach (MPF: micro-prism film; CG: clear glazing; W: wall. 
as shown in Fig. 11. All variants, except w6 (29.9\% sDA), are above the preferred sDA in non-shaded case (Fig. 12a). At this time, the influence of sunshade is higher than its impact in the second approach. This is expected due to gradually decreasing WWR values in this case (Fig. 12b), where w2 with $58.3 \%$ WWR is found to be the optimum variant getting sDA of $77 \%$. While in the previous approach, drc4 has got similar sDA of $75 \%$, although it has higher WWR of $75 \%$. Fig. 12 gives a detailed insight in introducing the

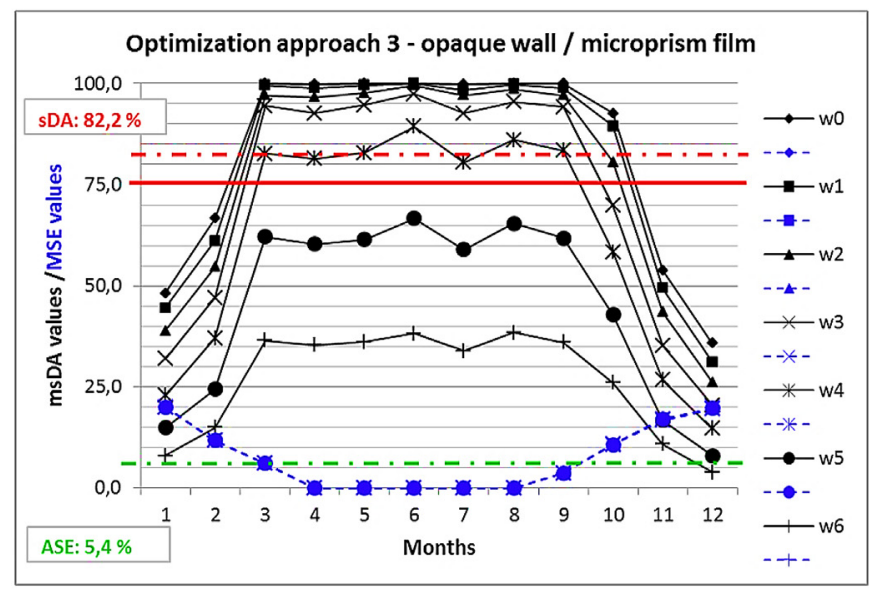

(a)

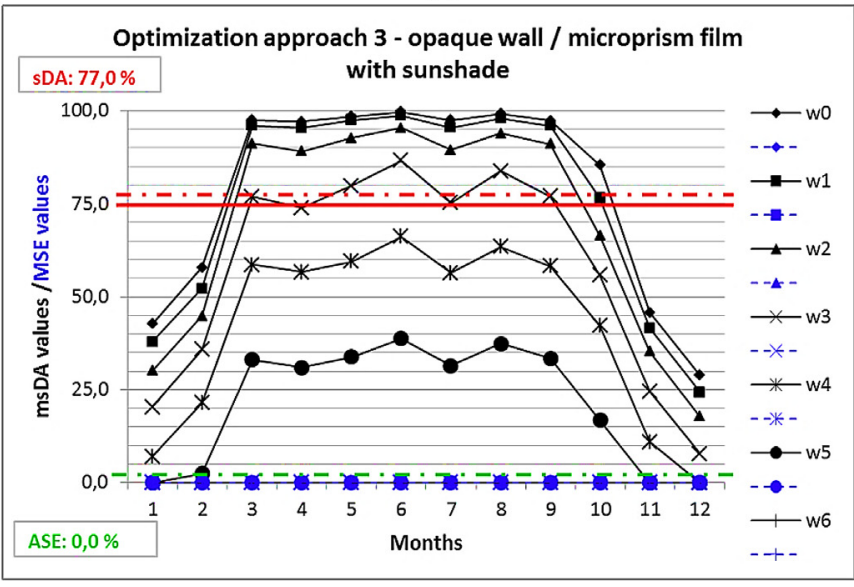

(b)

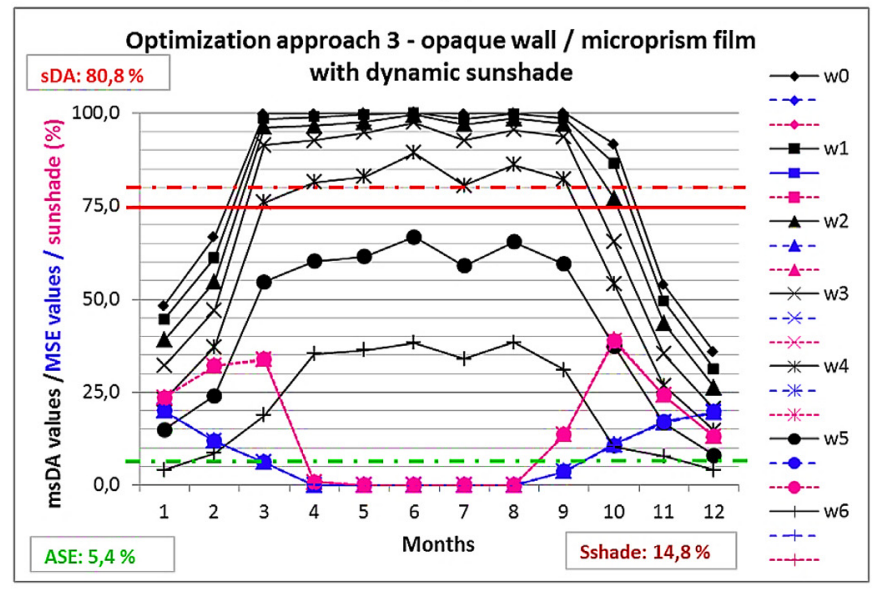

(c)

Fig. 12. Monthly breakdown of sDA for each window variant with micro-prism film and opaque wall material. contribution of MPF while reducing WWR and FWR in this final approach.

When dynamic sunshade is applied to reliably and effectively estimate the performance, w3 (80.8\% sDA) approaches the desired sDA initially; since, only the $8.3 \%$ rise in film area -modifying w 4 into w3- increased sDA from $65.4 \%$ to $80.2 \%$, with a $23 \%$ improvement. Enlarging the area of MPF in w2, w1 and w0 was ineffective in this sense. Their sDA ranged from 91.2 to 96.8 . Thus, we come up with the best solution getting WWR of $50 \%$ and combining FWR of 3/6 within the glazing. The use of film succeeded to achieve a stimulating daylit-environment, i.e. in w3 in the final optimization.

Additionally, when we consider MSE and sShade values in autumn there seems to be more sunshine than in spring; since, we get sun shade operating hours over and around 50\% for 3 months (August, September and October) in autumn, but only for one month (March) in spring. Accordingly, spring and autumn are not symmetric in terms of the weather data. 5.4\% ASE and 14.8\% sShade are read for w3.

One more comparison is noteworthy to discuss the impact of MPF in the second and third approaches. Even though both variants drc 3 and w3 are composed of three segments of MPF with $1 / 2$ FWR, their location in the window are dissimilar. In static sunshade situation, both of them leads to 63\% sDA. On the contrary, the former gets a higher sDA of $96 \%$ than the latter with an sDA of $80.8 \%$ in dynamic sunshade condition. Such a variation stems from the fact that the room itself with its highly glazed façade (75\% WWR) becomes very bright already in the second approach. A summary of findings including sDA for all variants is presented in Table 2.

The illuminance data are the basis for the daylight metrics. To gain further understanding and deep insight, the distribution of daylight illuminance are obtained at three specific timestamps near equinox and winter/summer solstices for the film-wall-clear glazing variants of the final approach. Figs. 14-16 present the illuminance readings at points located at the midline of the sensor plane, oriented perpendicular to the window wall. The sky conditions are clear and sunny to introduce the effect of film once again. Such graphical representations inform us about uniformity and useful daylight illuminance values (500-2000lx). They represent findings in static sunshade condition.

According to this, the greatest fluctuations are observed at noon in all periods. A greater number of points receive intolerably high daylight illuminance when FWR is above $1 / 2$ in $w 0-w 2$, at noon and in the afternoon near spring equinox (Fig. 13). The variant of $25 \%$ WWR without any film segment (w6) always falls below the illuminance threshold of $500 \mathrm{~lx}$. The addition of only one segment of film (w5), on the contrary, moves the distribution above that threshold line noticeably. Though, this is not enough to provide adequate daylight when we consider the entire workplane and all seasons in a year.

When $\mathrm{w} 3$ is the case, the majority of the points receive useful daylight illuminance throughout the day near spring equinox and summer solstice (Fig. 14). Distribution only exceeds the illuminance range at the sensor points adjacent to windows. Workplane, which

Table 2

sDA values (with dynamic sunshade).

\begin{tabular}{lllllll}
\hline rw0 & rw1 & rw2 & rw3 & rw4 & rw5 & rw6 \\
70.2 & 63.0 & 55.8 & 52.0 & 42.2 & 32.5 & 21.9 \\
\hline drc0 & drc1 & drc2 & drc3 & drc4 & drc5 & drc6 \\
69.6 & 86.4 & 92.2 & 94.6 & 96.2 & 96.5 & 97.3 \\
\hline w0 & $\mathbf{w 1}$ & $\mathbf{w 2}$ & $\mathbf{w 3}$ & $\mathbf{w 4}$ & $\mathbf{w 5}$ & $\mathbf{w 6}$ \\
96.8 & 94.9 & 91.2 & 80.2 & 65.4 & 47.2 & 21.3 \\
\hline
\end{tabular}




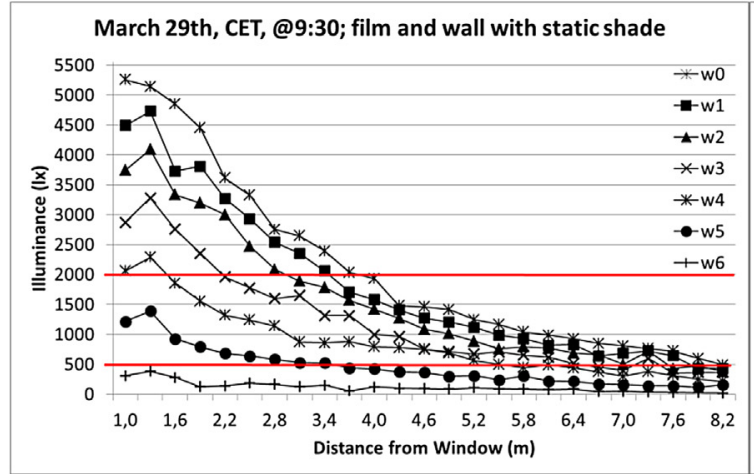

(a)

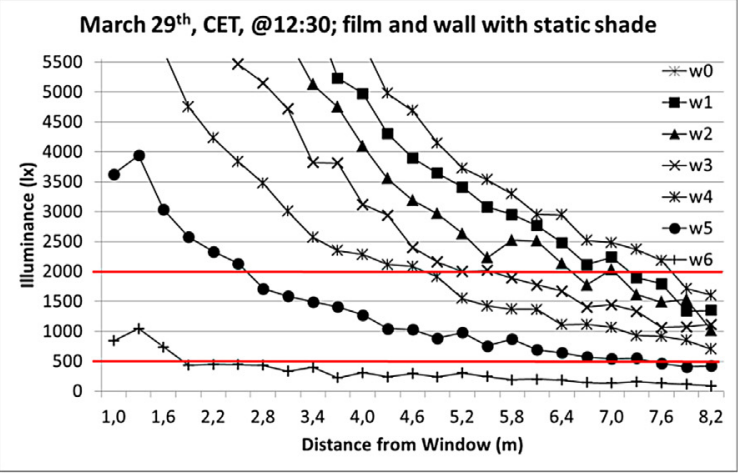

(b)

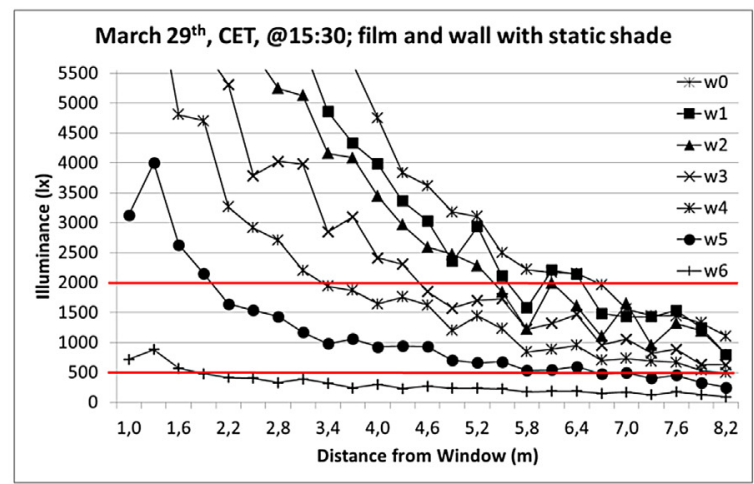

(c)

Fig. 13. Illuminance distribution at (a) 9:30, (b)12:30 and (c) 15:30 near the spring equinox.

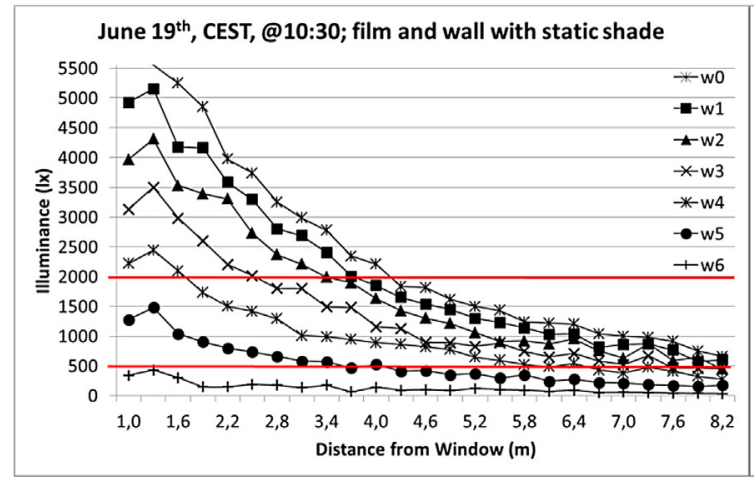

(a)

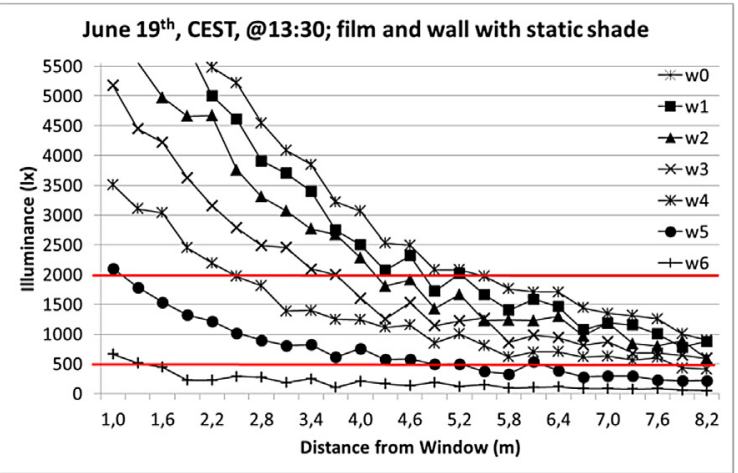

(b)

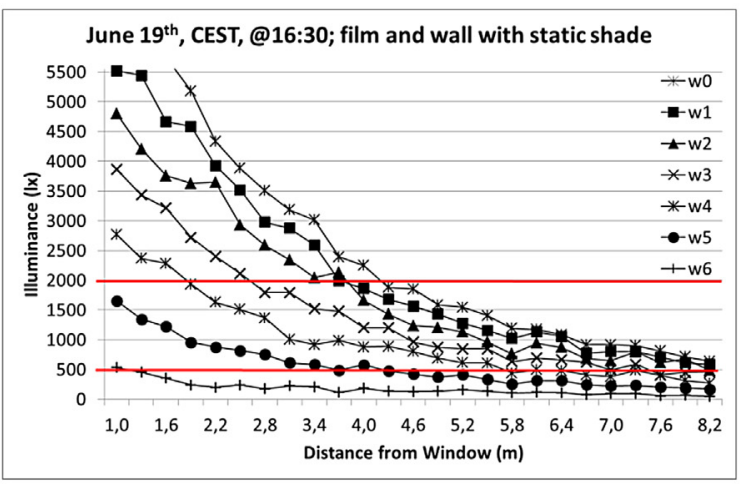

(c)

Fig. 14. Illuminance distribution at (a) 9:30, (b)12:30 and (c) 15:30 near summer solstice. 


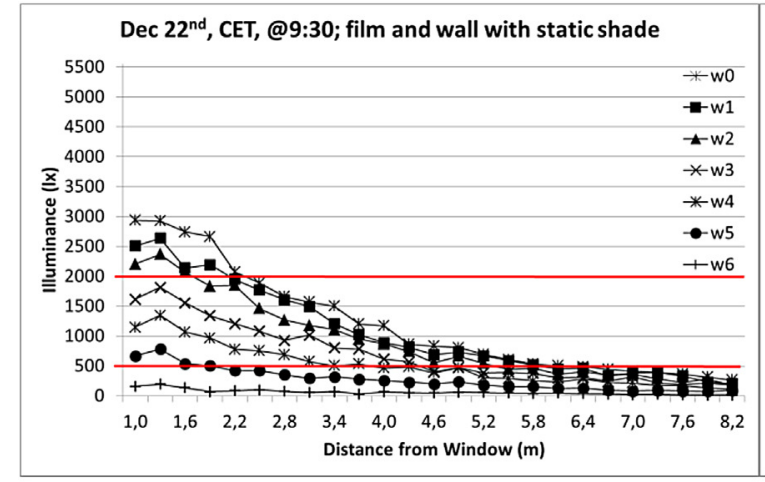

(a)

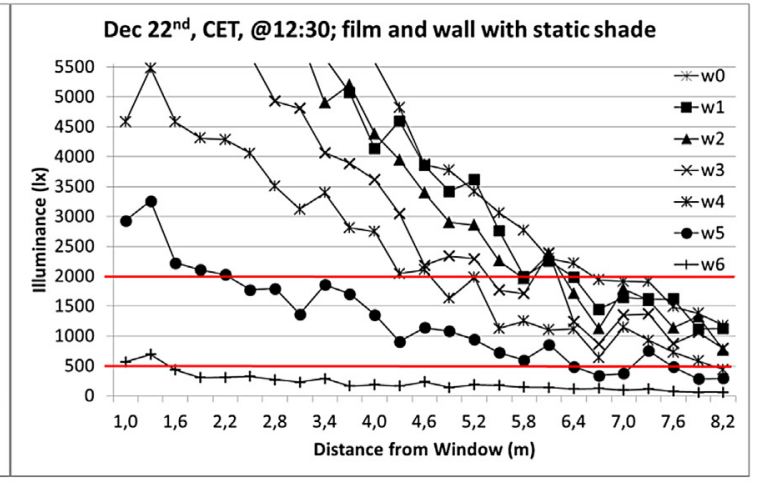

(b)

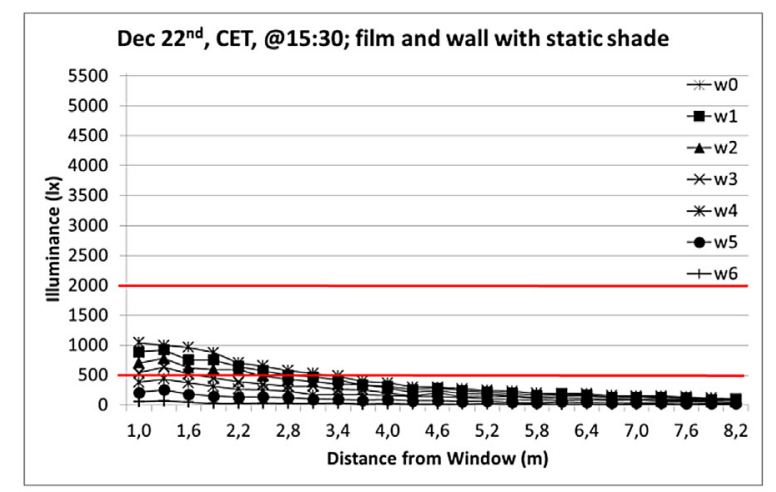

(c)

Fig. 15. Illuminance distribution at (a) 9:30, (b)12:30 and (c) 15:30 in the winter solstice.
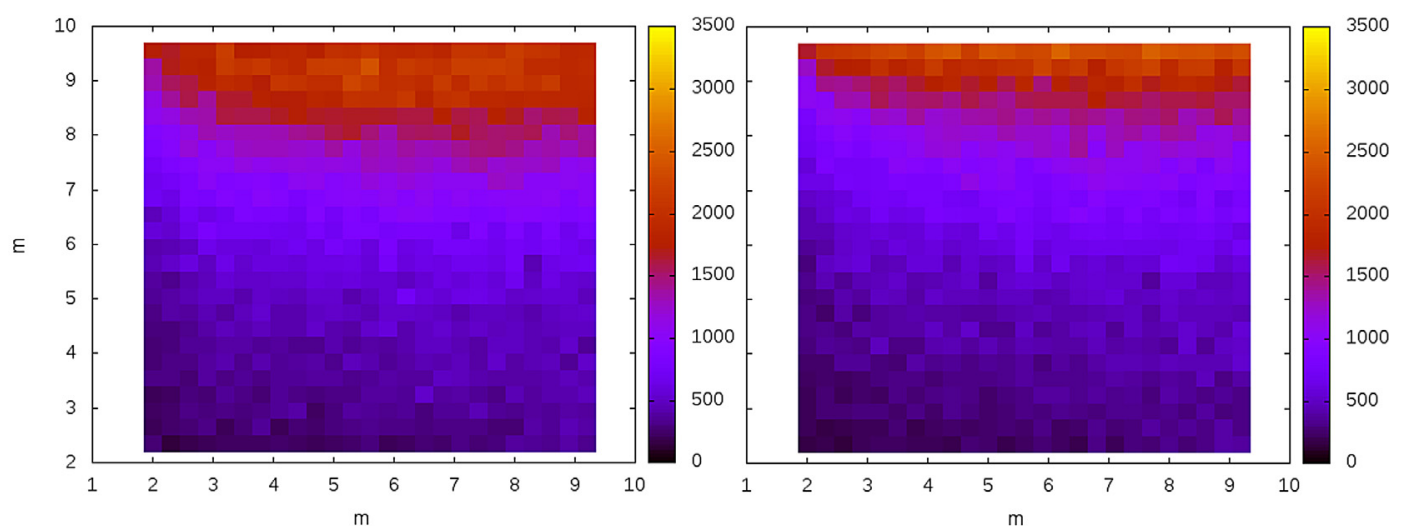

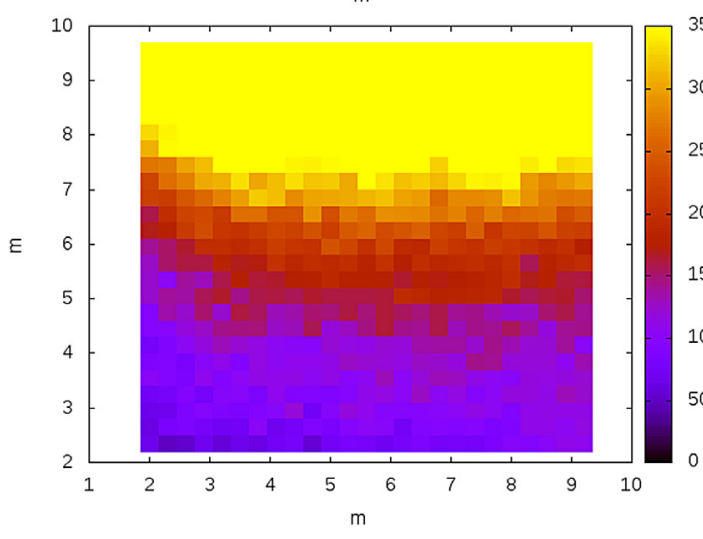

(a)

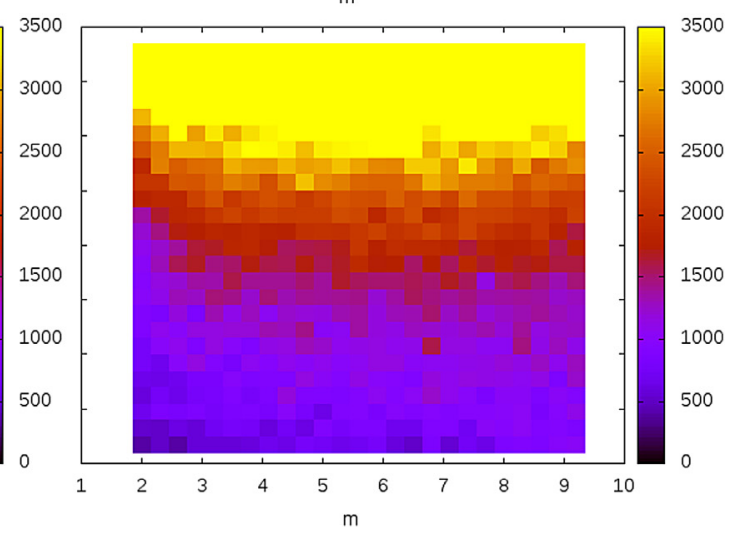

(b)

Fig. 16. Illuminance maps for (a) drc 2 and (b) w4 with static sunshade at 9:30 (upper row), and at 12:30 (lower row) near the spring equinox. 
is almost $4.0 \mathrm{~m}$ away from windows, gets higher illuminance near spring equinox; whereas, it is $2.8 \mathrm{~m}$ away from windows near summer solstice. The deepest area can benefit from the potential of daylight availability during spring and summer. The variants with larger sizes of film (w0-w2) result in an overall higher illuminance range, and extremely peak values on workplane adjacent to windows (almost $3.4 \mathrm{~m}$ from windows). This situation may lead to glare. That reminds us, once again, why we need to modify MPF area to use them in an effective way.

Winter solstice leads to the most unbalanced daylight performance in a day. In the morning, illuminance distribution of $\mathrm{w} 3$ falls within the UDI range on the work plane which is approx. $5.0 \mathrm{~m}$ away from the window, while unstable daylight frequencies of all window configurations are prevailing at noon. The rise of FWR in w0-2 does not change that distance in which daylight is effective. The room is quite dark as the illuminance is mainly below the threshold value of $500 \mathrm{~lx}$ in the afternoon. The afternoon hours in winter solstice remain as worse case conditions. Consequently, w3 performs well in summer and in spring regardless of the daytime sequences, when higher sun altitudes are valid. When compared to the summer, the springtime leads to a considerable daylight fluctuation at noon and in the afternoon. Even, it maintains the useful daylight illuminance on the great portion of work plane in the morning in the winter period.

Illuminance maps are generated additionally to distinguish and understand the performance of outcomes in detail, if the microprism film area is kept the same but its location and fraction have been modified in dissimilar window compositions and WWR. Specifically, we concentrated on the comparisons of drc2/versus w4 and drc3/versus w3 with static sunshade application. Fig. 16 illustrates false color distributions of drc2 and w4. The noteworthy outcome is that there is no much difference between drc3 and w3 with respect to the illuminance distributions. However, higher illuminance differences exist between $\operatorname{drc} 2$ and $\mathrm{w} 4$.

Both drc3 and drc2 result in higher illuminances in the static sunshade case at identical distances from the window, compared to w3 and w4. On the contrary, w3 and especially w4 reduces the area of high sun exposure, by still keeping sufficient illumination in the rear part of the room. More than two third of the work plane has got useful daylight illuminance during the most of the daytime. So, w3 and $\mathrm{w} 4$ performs better. In addition, the fact that drc3 and drc2 don't produce much higher illuminances than $\mathrm{w} 3$ and $\mathrm{w} 4$ is important; as this shows that the film produces the major fraction of illuminance in the room. Similar illuminance values can be achieved roughly despite a considerably lower WWR.

\section{Conclusions}

The focus is to optimize the area of both the window and the micro structured light redirecting film integrated in it. Obtaining the possible smallest value of WWR and FWR remains to be the objective of this optimization process maintaining the required sDA of $75 \%$. Three optimization approaches for a case room with a $75 \%$ WWR are developed employing EvalDRC simulations based on Radiance in all time stamps over the year. A data-driven model of the films' bidirectional scattering distribution function is contributed in these models. Each optimization approach includes window configurations of, first, clear glazing/opaque wall material; second, clear glazing/MPF; and third, MPF/opaque wall material together with the generated sunshade options. The choice of MPF is due to its ease of application and maintenance. It is integrated in the glass component and looks like a regular window.

Accordingly, the configuration w3 involving only 50\% WWR and the application of film with $1 / 2 \mathrm{FWR}$ is found to be the most effective one in the entire year. The broad and previous knowledge are supported; that is, introducing a micro-prism film in the regular window (i.e. when rw3 and w3 are compared) equally shadows off the direct sunlight, but lets it pass in a scattered and redirected way, thus raising the illuminance for the regions being further away from the window, even when the sun shade is drawn for the remaining clear glazing segment. The micro-prism film successfully and considerably enhances the sDA values. Such noteworthy consequences are specified. First, reducing the film area in half and replacing that part with opaque wall material also result in acceptable and satisfying sDA and msDA in half of the year. However, similar higher sDA values (approx. 90\%) are just slightly above the sDA of the most effective variant whose FWR is above $1 / 2$. This claims a clue for the unnecessary use of larger film areas. Increasing the film area over its optimum value does not make any significant impact on improving the daylight performance in the room. Second, reducing the film area in half when WWR is 75\% doesn't result in considerable change in high SDA values. The impact of clear glazing area and WWR are more powerful than the impact of film area. Third, the most effective variant satisfied the min. requirement of $500 \mathrm{~lx}$ deeper regions close to the rear wall (at $8.2 \mathrm{~m}$ away from windows) at summer solstice and equinoxes. This means that the depth of the perimeter region with adequate daylight is almost three times higher than the window height in this case. Fourth, the illuminance distribution does not differ considerably when the film area remains the same (i.e. drc3 and w3 are compared) in nonidentical locations.

Findings supported the effective use of redirecting film in various window configurations. Its ultimate success relies on design criteria which deal with the window area, film area and the window composition. This study provides such knowledge about how to design a convenient window with the integration of a DRC in terms of annual daylight autonomy requirements. Architects can get benefit from such approaches in their design process.

\section{Acknowledgments}

The first author was awarded a grant, as a Visiting Fellow, by The Scientific and Technological Research Council of Turkey (TUBITAK) (1059B191500018) and is grateful for its financial support.

\section{References}

[1] P. Ihm, A. Nemri, M. Krarti, Estimation of lighting energy savings from daylighting, Build. Environ. 44 (3) (2009) 509-514.

[2] K. Konis, Evaluating daylighting effectiveness and occupant visual comfort in a side-lit open-plan office building in San Francisco, California, Build. Environ. 59 (2013) 662-677.

[3] R.P. Leslie, Capturing the daylight dividend in buildings: why and how? Build. Environ. 38 (2) (2003) 381-385.

[4] C.F. Reinhart, J. Wienold, The daylighting dashboard- A simulation-based design analysis for daylit spaces, Build. Environ. 46 (2011) 386-396.

[5] A. Nabil, J. Mardaljevic, Useful daylight illuminances: a replacement for daylight factors, Energy Build. 38 (7) (2006) 905-913.

[6] C.F. Reinhart, J. Mardaljevic, Z. Rogers, Dynamic daylight performance metrics for sustainable building design, LEUKOS 3 (2006) 7-31.

[7] E. Nault, G. Peronato, E. Rey, M. Andersen, Review and critical analysis of early-design phase evaluation metrics for the solar potential of neighborhood designs, Build. Environ. 92 (2015) 679-691.

[8] IES Approved Method: Spatial Daylight Autonomy and Annual Sunlight Exposure, 2012. IES LM-83-12, USA.

[9] M.R. Fontenelle, L.E.G. Bastos, The multicriteria approach in the architecture conception: defining windows for an office building in Rio de Janerio, Build. Environ. 74 (2014) 96-105.

[10] I. Acosta, M.Á. Campano, J.F. Molina, Window design in architecture: analysis of energy savings for lighting and visual comfort in residential spaces, Appl. Energy 168 (2016) 493-506.

[11] C.E. Ochoa, M.B.C. Aries, E.J. van Loenen, J.L.M. Hensen, Considerations on design optimization criteria for windows providing low energy consumption and high visual comfort, Appl. Energy 95 (2012) 238-245.

[12] H. Shen, A. Tzempelikos, Sensitivity analysis on daylighting and energy performance of perimeter offices with automated shading, Build. Environ. 59 (2013) 303-314 
[13] C. Garnier, T. Muneer, L. McCauley, Super insulated aerogel windows: impact on daylighting and thermal performance, Build. Environ. 94 (2015) 231-238.

[14] International Energy Agency (IEA), Daylight in Buildings, first ed., IEA: The Lawrence Berkeley National Laboratory, Berkeley, CA, 2000.

[15] K. Konis, E.S. Lee, Measured daylighting potential of a static optical louver system under real sun and sky conditions, Build. Environ. 92 (2015) 347-359.

[16] C.B. Davila, On Advanced Daylighting Simulations and Integrated Performance Assessment of Complex Fenestration Systems for Sunny Climates (PhD. thesis), EPFL-École Polytechnique Fédérale de Lausanne, Lausanne, 2014.

[17] A. Thanachareonkit, J.L. Scartezzini, Modelling complex fenestration systems using physical and virtual models, Sol. Energy 84 (2010) 563-586.

[18] A. Thanachareonkit, E.S. Lee, A. McNeil, Empirical assessment of a prismatic daylight redirecting window film in a full-scale office test bed, LEUKOS 10 (2013) 19-45.

[19] P.A. Bennewitz, Review of simulating four classes of window materials for daylighting with non-standard BSDF using the simulation program Radiance, Comput. Phys. (2013) 1-24 arXiv:1307.4214v1 [physics.comp-ph].

[20] J. de Boer, Modelling indoor illumination by complex fenestration systems based on bidirectional photometric data, Energy Build. 38 (2006) 849-868.

[21] G. Ward, R. Mistrick, E.S. Lee, A. McNeil, J. Jonsson, Simulating the daylight performance of complex fenestration systems using bidirectional scattering distribution functions within Radiance, LEUKOS 7 (2011) 241-261.

[22] L.O. Grobe, S. Wittkopf, P.A. Bennewitz, J.C. Jonsson, M. Rubin, Experimental validation of bidirectional reflection and transmission distribution measurements of specular and scattering materials, in: Proceedings of SPIE7725, Photonics for Solar Energy Systems III, Brussels, Belgium, May 18, 2010;Brussels, Belgium, 2010, http://dx.doi.org/10.1117/12.854011.

[23] M. Andersen, E. Stokes, N. Gayeski, C. Browne, Using digital imaging to assess spectral solar-optical properties of complex fenestration materials: a new approach in videogoniophotometry, Sol. Energy 84 (2010) 549-562.

[24] L.O. Grobe, A. Noback, S. Wittkopf, Z.T. Kazanasmaz, Comparison of measured and computed BSDF of a daylight redirecting component, in: Proceedings of CISBAT, Lausanne, 2015, pp. 205-210.

[25] M. Andersen, J. de Boer, Goniophotometry and assessment of bidirectional photometric properties of complex fenestration systems, Energy Build. 38 (2006) 836-848.

[26] ASHRAE, International Climate Zone Definitions, in ANSI/ASHRAE/IESNA Standard 90.1, 2007.

[27] M. Fontoynont, Daylight Performance of Buildings, Earthscan, London, UK, 1999.

[28] T. Kazanasmaz, M. Günaydın, S. Binol, Artificial neural networks to predict daylight illuminance in office buildings, Build. Environ. 44 (2009) 1751-1757.

[29] M.R. Atif, J.A. Love, P. Littlefair, Daylighting Monitoring Protocols \& Procedures for Buildings, a Report of Task 21/Annex 29 Daylight in Buildings, October 1997.
[30] IGDB, International Glazing DataBase, Lawrence Berkeley National Laboratory, 2015. http://windowoptics.lbl.gov/data/igdb.

[31] R.D. Mitchell, J.C. Kohler, D.C. Curcija, L. Zhu, S. Vidanovic, S. Czarnecki, D. Arasteh, THERM. 6.3/WINDOW 6.3 NFRC Simulation Manual, Lawrence Berkeley National Laboratory, 2011.

[32] M. Krehel, J. Krampf, S. Wittkopf, Characterization and modelling of advanced daylight redirection systems with different goniophotometers, in: Proceedings of CISBAT, Lausanne, 2015, pp. 211-216.

[33] L. Mohanty, X. Yang, S.K. Wittkopf, Optical scatter measurement and analysis of innovative daylight scattering materials, Sol. Energy 86 (2012) 505-519.

[34] J.C. Jonsson, M.D. Rubin, A.M. Nilsson, A. Jonsson, A. Roos, Optical characterization of fritted glass for architectural applications, Opt. Mater. 31 (2009) 949-958.

[35] ASTM, Standard Practice for Goniometric Optical Scatter Measurements, ASTM E, ASTM International, 2005, pp. 2387-2405.

[36] R. Padiyath, B. Hao, C.A. Marttila, inventor; 3M Innovative Properties Company, assignee; Hybrid light redirecting and light diffusing constructions, Patent no: US 8995059 B2, 2015 March 31.

[37] D. Geisler-Moroder, A. Dür, A new ward BRDF model with bounded albedo, Comput. Graph. Forum 29 (4) (2010) 1391-1398.

[38] T. Smith, J. Guild, The CIE colorimetric standards and their use, Trans. Opt. Soc 33 (3) (1931) 73.

[39] CIE Pub. 15:2004, Colorimetry, CIE Central Bureau, Vienna, 2004.

[40] N. Lynn, L. Mohanty, S. Wittkopf, Color rendering properties of semitransparent thin-film PV modules, Build. Environ. 54 (2012) 148-158.

[41] M. Bodart, R. de Peñaranda, A. Deneyer, G. Flamant, Photometry and colorimetry characterisation of materials in daylighting evaluation tools, Build. Environ. 43 (2008) 2046-2058.

[42] G.W. Larson, R.A. Shakespeare, Rendering with Radiance: the Art and Science of Lighting Visualization, Morgan Kaufmann, San Francisco, CA, 1998.

[43] A. McNeil, C.J. Jonsson, D. Appelfeld, G. Ward, E.S. Lee, A validation of a raytracing tool used to generate bi-directional scattering distribution functions for complex fenestration systems, Sol. Energy 98 (2013) 404-414.

[44] R. Schregle, C. Bauer, L.O. Grobe, S. Wittkopf, EvalDRC: a tool for annua characterization of daylight redirecting components with photon mapping, in: Proceedings of CISBAT, Lausanne, 2015, pp. 217-222.

[45] R. Schregle, L.O. Grobe, S. Wittkopf, Progressive photon mapping for daylight redirecting components, Sol. Energy 114 (2015) 327-336.

[46] C. Bauer, A. Noback, Application for annual daylight assessment, in: Enhanced Photon Mapping in Radiance Workshop, Horw, Switzerland, 2015.

[47] C. Bauer, S. Wittkopf, Annual Daylight Simulations with EvalDRC: Assessing the Performance of Daylight, 2016. To be published in Journal of Facade Design and Engineering. (3-4), http://jfde.tudelft.nl/index.php/jfde/index.

[48] Chartered Institution of Building Services Engineers (CIBSE). Code for Lighting. London, 2002. 